\title{
The Awareness of Keratoconus among General Population in Saudi Arabia
}

\author{
Rahaf Mohammed Alruwaili ${ }^{*}$, Abeer Surihan Alharbi², Omar Ali Alghamdi ${ }^{3}$, \\ Yahya Abdulrahman Alyahya ${ }^{4}$, Nouf Mohammed Albalawi ${ }^{5}$, Sameer Sohail Alostaz ${ }^{6}$, \\ Omar Ahmed Asiri ${ }^{7}$, Khalid Alarfaj ${ }^{8}$ \\ ${ }^{1}$ College of Medicine, Jouf University, Sakaka, Saudi Arabia \\ ${ }^{2}$ Ophthalmology Department, Ohud Hospital, Madina, Saudi Arabia \\ ${ }^{3}$ Ophthalmology Department, King Fahad Hospital, Albaha, Saudi Arabia \\ ${ }^{4}$ Ophthalmology Department, Burydah Central Hospital, Qassim, Saudi Arabia \\ ${ }^{5}$ College of Medicine, Tabuk University, Tabuk, Saudi Arabia \\ ${ }^{6}$ Batterjee Medical College, Jeddah, Saudi Arabia \\ ${ }^{7}$ Faculty of Medicine, Taif University, Taif, Saudi Arabia \\ ${ }^{8}$ Ophthalmology Department, Imam Abdulrahman Bin Faisal University, Dammam, Saudi Arabia \\ Email: ^irahafalruwaili@gmail.com
}

How to cite this paper: Alruwaili, R.M Alharbi, A.S., Alghamdi, O.A., Alyahya, Y.A., Albalawi, N.M., Alostaz, S.S., Asiri, O.A. and Alarfaj, K. (2021) The Awareness of Keratoconus among General Population in Saudi Arabia. Open Journal of Ophthalmology, 11, 49-59.

https://doi.org/10.4236/ojoph.2021.111005

Received: December 31, 2020

Accepted: February 22, 2021

Published: February 25, 2021

Copyright $\odot 2021$ by author(s) and Scientific Research Publishing Inc. This work is licensed under the Creative Commons Attribution International License (CC BY 4.0).

http://creativecommons.org/licenses/by/4.0/ (c) (i) Open Access

\begin{abstract}
Introduction: Keratoconus (KCN) is one of the degenerative corneal disorders, which causes impairment in normal visual acuity with a higher prevalence in Saudi Arabia. The study aimed to assess the awareness and knowledge regarding $\mathrm{KCN}$, its risk factors, and management among the Saudi population. Materials and Methods: A survey was conducted using a pre-tested and validated questionnaire distributed through online platforms. A mixture of convenience and snowball sampling techniques was adopted for sample collection. Our analysis included a final sample size of 837 participant responses. The questionnaire had items related to sociodemographic characteristics (5 items), knowledge (10 items), and source of information ( 1 item). The mean knowledge scores were calculated and categorized (good, fair, and poor) to assess each participant's knowledge. Pearson's chi-square test was used to determine the statistical association between categorical variables. Results: The mean knowledge score was found to be $4.12 \pm 2.6$, and $67.5 \%$ of the participants showed "poor" scores. There was no statistically significant association of knowledge scores observed with any of the sociodemographic details. It was agreed by $76 \%$ and $42.5 \%$ that genetic predisposition and chronic eye inflammation could predispose to KCN. Only $38.1 \%(\mathrm{n}=157)$ agreed that $\mathrm{KCN}$ could be treated with optical glasses or contact lenses in the initial stages. Conclusion: The knowledge regarding $\mathrm{KCN}$ was not satisfactory among our study population. There is a need to create an increased level of
\end{abstract}


awareness for KCN. Health awareness programs and community campaigns should be organized to raise awareness regarding $\mathrm{KCN}$ and better eye health care utilization.

\section{Keywords}

Ophthalmology, Inflammation, Keratoconus, Blindness

\section{Introduction}

Keratoconus $(\mathrm{KCN})$ is a degenerative bilateral, progressive disorder characterized by ectasia, thinning, and increased curvature of the cornea and is associated with loss of visual acuity, particularly with high-order aberrations [1]. The exact etiology of $\mathrm{KCN}$ is still in doubt, and a genetic basis has been suspected due to the clustering of cases within families and in twins [2] [3].

Epidemiological data shows that the incidence of KCN ranges from 1.25 to 25 per million-population depending upon the geographic location. The onset is usually at puberty that advances until the 3rd to 4th decade if life generally shows no gender predominance [4] [5] [6]. A study done by Kennedy et al. in Minnesota, USA, reported a prevalence of $0.054 \%$ [5]. In the Kingdom of Saudi Arabia, an incidence of 20 cases per 100,000 has been reported in Asir province with more severe and rapidly progressive cases [7]. Another study done in KSA among children and adolescents reported a prevalence of $4.79 \%$ [8].

$\mathrm{KCN}$ is reported to be associated with down syndrome, connective tissue disorders, Leber congenital amaurosis, Gas-Permeable (GP) contact lens wear, and chronic eye rubbing [1] [9]. KCN is usually classified as a non-inflammatory corneal ectatic disease and may remain undetected (subclinical) as asymmetric oblique astigmatism till puberty. Thus early detection and timely diagnosis are very much crucial to prevent the late complication of KCN. Many sophisticated tools for mapping the cornea contours are utilized in the diagnosis of $\mathrm{KCN}$, such as the Ocular Response Analyzer, spectral-domain optical coherence tomography (OCT), Confocal microscopy, Fourier Transform Infrared (FTIR), and Optical Quality Analysis System [10]. The screening programs for KCN could utilize simple, inexpensive imaging devices like Keratometry (manual keratometer) and Corneal Topography. Authors have utilized some indices like Keratoconus Prediction Index (KPI-Klyce-Maeda group) and Rabinowithz KISA \% index to discriminate Keratoconus and subclinical Keratoconus [11] [12].

One of the challenges that ophthalmologists face is halting disease progression in asymptomatic subclinical stages. Even though patients with KCN show significant myopia, it is not a criterion for its diagnosis. Asymmetrical corneal astigmatism and focal stromal thinning are considered a significant clinical presentation in $\mathrm{KCN}$. In the diagnosis of $\mathrm{KCN}$, symmetric astigmatism is not a criterion. Thus, diagnostic tools like tomography, topography, and pachymetry help evaluate corneal thinning and asymmetric astigmatism in KCN [13] [14]. In 
mild cases of KCN, rigid contact lenses or spectacles are usually sufficient to reduced visual acuity [15]. People need to be informed about the potential risks and importance of early detection of $\mathrm{KCN}$. There is limited information on awareness and knowledge regarding $\mathrm{KCN}$ in Saudi Arabia among the general population. Hence this study was aimed to assess the understanding and knowledge concerning KCN in Saudi citizens.

\section{Materials and Method}

A cross-sectional observational study was conducted using a pre-tested and validated questionnaire in the Arabic language. Permission to conduct study was obtained from the Research and Ethics Committee of the institution. The study included only adult Saudi citizens who are aged above 18 years and those gave consent to participate. The questionnaire was sent online to participants through social network applications. A minimum sample size of 628 was calculated based in a pilot study conducted on 30 participants using the formula,

$$
n=\frac{Z_{1-\alpha / 2} \sqrt{P_{0}\left(1-P_{0}\right)}+Z_{1-\beta} \sqrt{P_{\alpha}\left(1-P_{\alpha}\right)}}{\left(P_{\alpha}-P_{0}\right)^{2}}
$$

We used a combination of convenience and snowball sampling techniques to collect data from different provinces of Saudi Arabia.

The original version of questionnaire was developed in English and was then validated. Content validity, face validity, and construct validity of the developed questionnaire were examined. An expert committee evaluation and Focused Group Discussions (FGDs) were conducted to determine content validity and face validity. The questionnaire showed good Internal consistency reliability (Cronbach's alpha $=0.861)$. The English version was then translated into Arabic language by a bilingual translator who was proficient in both English and Arabic language. Another expert back translated the Arabic version into English, which showed excellent linguistic validity. The questionnaire consisted of two sections; Section A included statement of confidentiality and Anonymity, followed by sociodemographic details and Section B had closed ended-items that measured the knowledge and associated variables regarding $\mathrm{KCN}$. The items that measured knowledge were used to calculate total knowledge according to the responses where each correct answer for each item was given a score "1" and wrong answer a score "0". For calculating knowledge, we converted the total knowledge scores into percentages, which was then categorized "Good" (scores $\geq 80 \%$ ), "Fair" (scores 60\% - 79\%), and "Poor" (<60\%).

\section{Statistical Analysis}

The responses obtained were entered in Microsoft Excel and was subjected to data cleaning was done to make the analysis easy. The data was then subjected to statistical analysis by an independent biostatistician. We used SPSS version 23 (IBM Corp. USA) for carrying out the required statistical analysis. Continuous 
variables were expressed as means with standard deviations and categorical variables were presented as frequencies and percentages. Students " $t$ " tests and Analysis of Variance (ANOVA) were used to evaluate the differences in mean knowledge scores across various sociodemographic characteristics. Association between categorical variables was tested using Pearson's Chi-square test. A probability value (p-value) less than 0.05 was considered to be statistically significant.

\section{Results}

Our study assessed the awareness and knowledge related to Keratoconus (KCN) among Saudi citizens. We received 1032 responses, but the final analysis included only 837 participants who had agreed to participate and also answered all the items in the questionnaire. The sociodemographic characteristics showed that $74.8 \%$ were females, and $25.2 \%$ were males. The age-wise distribution showed that $43.9 \%$ belonged to $\geq 36$ years group, $20.9 \%$ from 26 - 35 years, $32 \%$ from 18 - 25 years, and only $3.2 \%$ from $<18$ years. The distribution of participants according to region, education, and income status are given in (Table 1).

Our analysis showed that the awareness regarding $\mathrm{KCN}$ in our study population was only $49.2 \%(n=412)$. Therefore we assessed the knowledge related to $\mathrm{KCN}$ its risk factors, symptoms, and management among these 412 participants only. The questionnaire had ten items related to knowledge, and each correct response for these items was given a score of 1 , whereas wrong, incorrect answer

Table 1. Socio-demographic characteristics $(n=837)$.

\begin{tabular}{|c|c|c|c|}
\hline & & $\mathbf{N}$ & $\%$ \\
\hline \multirow{2}{*}{ Gender } & Female & 626 & 74.79 \\
\hline & Male & 211 & 25.21 \\
\hline \multirow{4}{*}{ Age } & Less than 18 & 27 & 3.23 \\
\hline & $18-25$ & 268 & 32.02 \\
\hline & $26-35$ & 175 & 20.91 \\
\hline & 36 or more & 367 & 43.85 \\
\hline \multirow{5}{*}{ Region } & Central & 213 & 25.45 \\
\hline & Eastern & 47 & 5.62 \\
\hline & Northern & 266 & 31.78 \\
\hline & Southern & 28 & 3.35 \\
\hline & Western & 282 & 33.69 \\
\hline \multirow{4}{*}{ Education } & Less than High school & 8 & 0.96 \\
\hline & High school & 130 & 15.53 \\
\hline & Bachelors and diploma & 573 & 68.46 \\
\hline & Masters and $\mathrm{PhD}$ & 126 & 15.05 \\
\hline \multirow{3}{*}{ Income status } & Below average & 33 & 3.94 \\
\hline & Average & 562 & 67.14 \\
\hline & Above average & 242 & 28.91 \\
\hline
\end{tabular}


was given no score. Thus the total maximum score one participant could get was 10. The mean total knowledge score in our study was found to be $4.12 \pm 2.6$. We categorized the total score based on the percentages into Good $(\geq 80 \%)$, fair $(60 \%$ - $79 \%)$, and Poor $(<60 \%)$. The analysis showed that only $11.7 \%$ had good knowledge, and $67.5 \%$ showed poor knowledge related to KCN (Figure 1).

We compared the knowledge scores between different sociodemographic characters (Table 2). There were no statistically significant differences noted

Table 2. Knowledge related to KCN and its relationship with socio-demographic factors $(\mathrm{n}=412)$.

\begin{tabular}{|c|c|c|c|c|c|c|}
\hline & & \multicolumn{3}{|c|}{ Knowledge } & \multirow{2}{*}{ Total } & \multirow{2}{*}{ p value ${ }^{*}$} \\
\hline & & Good & Fair & Poor & & \\
\hline \multirow{2}{*}{ Gender } & Female & $\begin{array}{c}37 \\
(12 \%)\end{array}$ & $\begin{array}{c}64 \\
(20.8 \%)\end{array}$ & $\begin{array}{c}207 \\
(67.2 \%)\end{array}$ & $\begin{array}{c}308 \\
(100.0 \%)\end{array}$ & \multirow{2}{*}{0.925} \\
\hline & Male & $\begin{array}{c}11 \\
(10.6 \%)\end{array}$ & $\begin{array}{c}22 \\
(21.2 \%)\end{array}$ & $\begin{array}{c}71 \\
(68.3 \%)\end{array}$ & $\begin{array}{c}104 \\
(100.0 \%)\end{array}$ & \\
\hline \multirow{4}{*}{ Age (years) } & $<18$ & $\begin{array}{c}1 \\
(7.7 \%)\end{array}$ & $\begin{array}{c}3 \\
(23.1 \%)\end{array}$ & $\begin{array}{c}9 \\
(69.2 \%)\end{array}$ & $\begin{array}{c}13 \\
(100.0 \%)\end{array}$ & \multirow{4}{*}{0.530} \\
\hline & $18-25$ & $\begin{array}{c}11 \\
(8.3 \%)\end{array}$ & $\begin{array}{c}26 \\
(19.7 \%)\end{array}$ & $\begin{array}{c}95 \\
(72.0 \%)\end{array}$ & $\begin{array}{c}132 \\
(100.0 \%)\end{array}$ & \\
\hline & $26-35$ & $\begin{array}{c}15 \\
17.4 \%\end{array}$ & $\begin{array}{c}19 \\
22.1 \%\end{array}$ & $\begin{array}{c}52 \\
60.5 \%\end{array}$ & $\begin{array}{c}86 \\
100.0 \%\end{array}$ & \\
\hline & $\geq 36$ & $\begin{array}{c}21 \\
11.6 \%\end{array}$ & $\begin{array}{c}38 \\
21.0 \%\end{array}$ & $\begin{array}{c}122 \\
67.4 \%\end{array}$ & $\begin{array}{c}181 \\
100.0 \%\end{array}$ & \\
\hline \multirow{5}{*}{ Region } & Central & $\begin{array}{c}12 \\
11.4 \%\end{array}$ & $\begin{array}{c}20 \\
19.0 \%\end{array}$ & $\begin{array}{c}73 \\
69.5 \%\end{array}$ & $\begin{array}{c}105 \\
100.0 \%\end{array}$ & \multirow{5}{*}{0.973} \\
\hline & Eastern & $\begin{array}{c}3 \\
13.0 \%\end{array}$ & $\begin{array}{c}6 \\
26.1 \%\end{array}$ & $\begin{array}{c}14 \\
60.9 \%\end{array}$ & $\begin{array}{c}23 \\
100.0 \%\end{array}$ & \\
\hline & Northern & $\begin{array}{c}16 \\
12.2 \%\end{array}$ & $\begin{array}{c}30 \\
22.9 \%\end{array}$ & $\begin{array}{c}85 \\
64.9 \%\end{array}$ & $\begin{array}{c}131 \\
100.0 \%\end{array}$ & \\
\hline & Southern & $\begin{array}{c}1 \\
7.1 \%\end{array}$ & $\begin{array}{c}4 \\
28.6 \%\end{array}$ & $\begin{array}{c}9 \\
64.3 \%\end{array}$ & $\begin{array}{c}14 \\
100.0 \%\end{array}$ & \\
\hline & Western & $\begin{array}{c}16 \\
11.5 \%\end{array}$ & $\begin{array}{c}26 \\
18.7 \%\end{array}$ & $\begin{array}{c}97 \\
69.8 \%\end{array}$ & $\begin{array}{c}139 \\
100.0 \%\end{array}$ & \\
\hline \multirow{4}{*}{ Education level } & Less than high school & $\begin{array}{c}0 \\
0.0 \%\end{array}$ & $\begin{array}{c}0 \\
0.0 \%\end{array}$ & $\begin{array}{c}4 \\
100.0 \%\end{array}$ & $\begin{array}{c}4 \\
100.0 \%\end{array}$ & \multirow{4}{*}{0.750} \\
\hline & Bachelors and diploma & $\begin{array}{c}30 \\
10.6 \%\end{array}$ & $\begin{array}{c}59 \\
20.9 \%\end{array}$ & $\begin{array}{c}193 \\
68.4 \%\end{array}$ & $\begin{array}{c}282 \\
100.0 \%\end{array}$ & \\
\hline & High school & $\begin{array}{c}10 \\
15.6 \%\end{array}$ & $\begin{array}{c}13 \\
20.3 \%\end{array}$ & $\begin{array}{c}41 \\
64.1 \%\end{array}$ & $\begin{array}{c}64 \\
100.0 \%\end{array}$ & \\
\hline & Masters and $\mathrm{PhD}$ & $\begin{array}{c}8 \\
12.9 \%\end{array}$ & $\begin{array}{c}14 \\
22.6 \%\end{array}$ & $\begin{array}{c}40 \\
64.5 \%\end{array}$ & $\begin{array}{c}62 \\
100.0 \%\end{array}$ & \\
\hline \multirow{3}{*}{ Income status } & Above average & $\begin{array}{c}13 \\
10.9 \%\end{array}$ & $\begin{array}{c}28 \\
23.5 \%\end{array}$ & $\begin{array}{c}78 \\
65.5 \%\end{array}$ & $\begin{array}{c}119 \\
100.0 \%\end{array}$ & \multirow{3}{*}{0.139} \\
\hline & Average & $\begin{array}{c}30 \\
10.8 \%\end{array}$ & $\begin{array}{c}56 \\
20.2 \%\end{array}$ & $\begin{array}{c}191 \\
69.0 \%\end{array}$ & $\begin{array}{c}277 \\
100.0 \%\end{array}$ & \\
\hline & Below average & $\begin{array}{c}5 \\
31.3 \%\end{array}$ & $\begin{array}{c}2 \\
12.5 \%\end{array}$ & $\begin{array}{c}9 \\
56.3 \%\end{array}$ & $\begin{array}{c}16 \\
100.0 \%\end{array}$ & \\
\hline
\end{tabular}

* a $\mathrm{p}$ value $<0.05$ is considered statistically significant. 


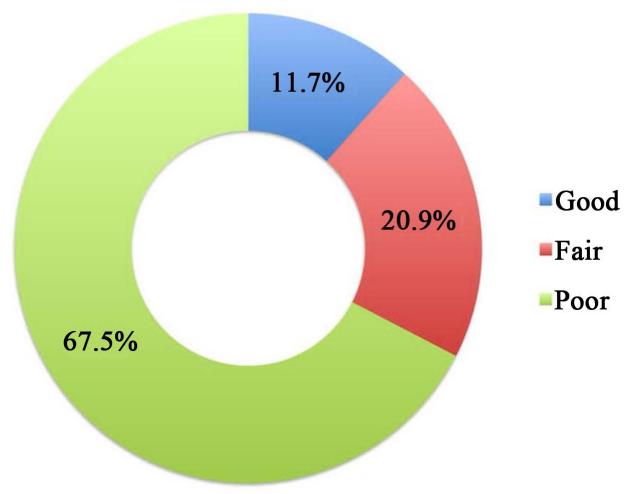

Figure 1. Knowledge related to Keratoconus $(n=412)$.

between male and female participants $(\mathrm{p}=0.925)$. It was found that participants in the 26 - 35 years age group (17.4\%) showed comparatively better knowledge scored compared to other age groups but didn't find any statistically significant association $(\mathrm{p}=0.530)$. There were also no significant differences observed in knowledge scores in participants based on region $(p=0.973)$, education level ( $p$ $=0.750)$, and income status $(\mathrm{p}=0.139)($ Table 2$)$.

Only $27.2 \%(\mathrm{n}=113)$ gave the correct definition of the Keratoconus, and 76\% $(\mathrm{n}=313)$ believed that KCN doesn't have a genetic predisposition. About $47.1 \%$ ( $n=194)$ of the participants agreed that KCN would lead to myopia if not appropriately managed, and $42.5 \%(\mathrm{n}=175)$ believed that chronic eye inflammation is a risk factor KCN. It was observed that only $25.7 \%(\mathrm{n}=106)$ agreed that constant itching or rubbing of eyes would lead to KCN, and 57\% $(n=235)$ cause vision deterioration if not treated on time.

The assessment of knowledge related to treatment of $\mathrm{KCN}$ showed that $61.4 \%$ $(\mathrm{n}=253)$ of participants agreed that Keratoconus patients need constant follow-up with an ophthalmologist. It was observed that $28.9 \%(\mathrm{n}=119)$ of participants believed that eye drops could be used in the first stage of $\mathrm{KCN}$, whereas $12.1 \%$ thought that corneal transplantation and $4.9 \%$ believed installing a ring in the cornea could be the treatment. Only $38.1 \%(n=157)$ agreed KCN could be treated with optical glasses or contact lenses. The questions for treatment for advanced-stage showed that $71.8 \%(\mathrm{n}=296)$ of participants had the opinion that surgery could be the choice, whereas $11.4 \%(n=47)$ mentioned it as eye drops, $6.3 \%(\mathrm{n}=26)$ as eyeglasses, and $5.8 \%(\mathrm{n}=24)$ as contact lenses. When we assessed the source of information related to KCN knowledge, $14.8 \%(\mathrm{n}=61)$ mentioned it as doctors or health care workers, $22.8 \%(\mathrm{n}=94)$ as social networks, and $20.1 \%(n=83)$ friends or relatives.

\section{Discussion}

To our knowledge, this was the first study that assessed the knowledge and awareness regarding Keratoconus (KCN) among the general population in the Kingdom of Saudi Arabia. The findings showed that the understanding and knowledge regarding KCN was poor among our study population irrespective of 
the sociodemographic characteristics. Studies show that the prevalence of KCN in the Saudi population is much higher compared to other Middle East countries [7] [8] [16] [17]. Despite the higher prevalence, our study population demonstrated poor knowledge regarding $\mathrm{KCN}$.

Evidence shows that KCN has a multifactorial etiology that offers a high genetic predisposition, and several genomic loci and genes have been identified in this regard [2] [18] [19]. In our study, only $24 \%$ of the participants believed that KCN has genetic susceptibility, which shows poor knowledge of this eye disorder. The ethnic variations in the prevalence of $\mathrm{KCN}$ also strongly support the genetic predisposition. The prevalence of $\mathrm{KCN}$ in Caucasian populations was 50 in 100,000, whereas this was approximately double in Negroids and Latinos [20] [21]. However, some environmental factors also pose a greater risk for the development of KCN, such as eye rubbing, atopy, and UV light exposure [22] [23] [24] [25]. Remarkably, only very few participants were aware of the risk factors of $\mathrm{KCN}$, in which $25.7 \%$ believed that frequent eye rubbing or itching causes the disease. Knowledge related to risk factors is essential as this would motivate the people to attend the screening, which could diagnose the disease at its incipient stage. Even though $\mathrm{KCN}$ is a progressive disorder, several treatments can improve the vision and, at times, reverse the damage [26]. Besides, the economic burden of $\mathrm{KCN}$ treatment is high to the patients and their caretakers, and hence, it is imperative to recognize those with the diseases at an early stage.

Currently, several ocular screening techniques such as corneal topography (CT) and biomechanical evaluation have been used, of which CT is commonly used for primary detection of KCN [27]. The diagnosis of subclinical KCN is often challenging for ophthalmologists. In subclinical $\mathrm{KCN}$, there would be mild topographic changes in the cornea with the normal-appearing cornea in keratometry, retinoscopy, or slit-lamp biomicroscopy [28] [29]. In clinical KCN, topography, tomography, and pachymetry are used as the primary diagnostics, which would reveal corneal thinning and asymmetric astigmatism arising in the location of corneal protrusion [13].

The management of $\mathrm{KCN}$ depends on the stage of diseases and their progression. In the non-progressive stage, the first priority should be given for correction of vision, and in case of progressing type, emphasis should be given to slow the progression [30]. In the early stages of $\mathrm{KCN}$, vision correction could be done with spectacles and soft contact lenses [31]. In our study, only $38.1 \%$ agreed that optical glasses and contact lenses could be used for vision correction at the early stages of KCN. In case of moderate-to-advanced KCN cases, vision correction, could be done using Rigid Gas-Permeable (RGP) contact lenses or scleral lenses, as these lenses are superior to neutralize the ocular aberrations associated with the keratoconic ectasia by creating a tear pool between the lens and the cornea [32]. Scleral lenses are usually recommended as they provide excellent vision and improved comfort compared to RGP contact lenses that often show intolerance, allergic reactions, corneal abrasions, and neovascularization [20] [33]. Another 
treatment that is done to limit the progression of $\mathrm{KCN}$ is Corneal collagen crosslinking (CXL), which increases stromal rigidity, thereby stabilizing keratectasia progression [34]. Surgical correction of KCN is considered the last resort in the advanced stages if the vision is severely compromised. The corneal transplant is the common procedure done where the cornea from a donor is replaced partially or totally to the recipient [35]. Collagen crosslinking is also a promising and effective treatment for halting keratectasia's progression in KCN patients [36].

The study findings demonstrate a lack of knowledge among the Saudi population related to $\mathrm{KCN}$, its risk factors, and management. There is a need to increase the public awareness and knowledge of $\mathrm{KCN}$ for prevention, early treatment, and utilization of eye care services in the Kingdom. This could minimize the visual impairment and unwanted economic burden for eye surgeries. World Sight Day is celebrated globally on the second Thursday of October to increase global attention on blindness and vision impairment [37]. There is a drastic improvement in health awareness programs in Saudi Arabia in the past years, and public eye health awareness campaigns should focus on social media and the Internet to cover the younger population. Currently, there are no national screening programs for eye disorders in Saudi Arabia; hence the author of this research suggests and requests the ministry of health to incorporate such programs as this can improve the awareness and knowledge related to KCN and other eye disorders.

Some of the limitations of the study should be addressed before generalizing our findings. As this is a cross-sectional survey, a major limitation of the study is selection bias as we included only participants who were willing to participate. Secondly, our study may have encountered response bias as the participants were asked to self-report. We tried to reduce this bias by incorporating closed-ended knowledge items with a simple, exhaustive set of answer options.

\section{Conclusion}

The study's findings show that awareness and knowledge related to $\mathrm{KCN}$ are lacking among the study population. The data we provided may help policymakers identify the target populations for KCN prevention and health education. Public health awareness and screening programs are needed in Saudi Arabia to address the lack of knowledge about $\mathrm{KCN}$, its preventive and curative measures. As KCN has high genetic susceptibility, topographic screening in elementary schools could be done in children for early detection and disease stabilization.

\section{Acknowledgements}

All the authors would like to express their deep gratitude and thanks to all the participants for responding and giving consent to participate in this research. Also we thank Dr. Fawaz Pullishery for carrying for the required statistical analysis of our data. 


\section{Conflicts of Interest}

None of authors have any conflict of interest to declare regarding the publication of this manuscript.

\section{References}

[1] Krachmer, J.H., Feder, R.S. and Belin, M.W. (1984) Keratoconus and Related Noninflammatory Corneal Thinning Disorders. Survey of Ophthalmology, 28, 293-322. https://doi.org/10.1016/0039-6257(84)90094-8

[2] Nowak, D.M. and Gajecka, M. (2011) The Genetics of Keratoconus. Middle East African Journal of Ophthalmology, 18, 2-6.

https://doi.org/10.4103/0974-9233.75876

[3] Nielsen, K., Hjortdal, J., Pihlmann, M. and Corydon, T.J. (2012) Update on the Kera-Toconus Genetics. Acta Ophthalmologica, 91, 106-113. https://doi.org/10.1111/j.1755-3768.2012.02400.x

[4] McGhee, C.N. (2009) Sir Norman McAlister Gregg Lecture: 150 Years of Practical Observations on the Conical Cornea-What Have We Learned? Clinical \& Experimental Ophthalmology, 37, 160-176. https://doi.org/10.1111/j.1442-9071.2009.02009.x

[5] Kennedy, R.H., Bourne, W.M. and Dyer, J.A. (1986) A 48-Year Clinical and Epidemiologic Study of Keratoconus. American Journal of Ophthalmology, 101, 267-273. https://doi.org/10.1016/0002-9394(86)90817-2

[6] Nielsen, K., Hjortdal, J., Aagaard Nohr, E. and Ehlers, N. (2007) Incidence and Prevalence of Keratoconus in Denmark. Acta Ophthalmologica Scandinavica, 85, 890-892. https://doi.org/10.1111/j.1600-0420.2007.00981.x

[7] Assiri, A.A., Yousuf, B.I., Quantock, A.J. and Murphy, P.J. (2005) Incidence and Severity of Keratoconus in Asir Province, Saudi Arabia. British Journal of Ophthalmology, 89, 1403-1406. https://doi.org/10.1136/bjo.2005.074955

[8] Torres Netto, E.A., Al-Otaibi, W.M., Hafezi, N.L., Kling, S., Al-Farhan, H.M., Randleman, J.B., et al. (2018) Prevalence of Keratoconus in Paediatric Patients in Riyadh, Saudi Arabia. British Journal of Ophthalmology, 102, 1436-1441. https://doi.org/10.1136/bjophthalmol-2017-311391

[9] Elder, M.J. (1994) Leber Congenital Amaurosis and Its Association with Keratoconus and Keratoglobus. Journal of Pediatric Ophthalmology and Strabismus, 31, 38-40.

[10] Fernández Pérez, J., Valero Marcos, A. and Martínez Peña, F.J. (2014) Early Diagnosis of Keratoconus: What Difference Is It Making? British Journal of Ophthalmology, 98, 1465-1466. https://doi.org/10.1136/bjophthalmol-2014-305120

[11] Vazirani, J. and Basu, S. (2013) Keratoconus Current Perspectives. Clinical Ophthalmology, 7, 2019-2030. https://doi.org/10.2147/OPTH.S50119

[12] Sedghipour, M.R., Sadigh, A.L. and Motlagh, B.F. (2012) Revisiting Corneal Topography for the Diagnosis of Keratoconus: Use of Rabinowitz's KISA\% Index. Clinical Ophthalmology, 6, 181-184. https://doi.org/10.2147/OPTH.S24219

[13] Tang, M., Li, Y., Chamberlain, W., Louie, D.J., Schallhorn, J.M. and Huang, D. (2016) Differentiating Keratoconus and Corneal Warpage by Analyzing Focal Change Patterns in Corneal Topography, Pachymetry, and Epithelial Thickness Maps. Investigative Ophthalmology \& Visual Science, 57, OCT544-OCT549. https://doi.org/10.1167/iovs.15-18938 
[14] Belin, M.W. and Duncan, J.K. (2016) Keratoconus: The ABCD Grading System. Klinische Monatsblätter für Augenheilkunde, 233, 701-707. https://doi.org/10.1055/s-0042-100626

[15] Atebara, N.H., Asbell, P.A. and Azar, D.T. (2009) Contact Lens, Chapter 5. In: Scuta, G.L., Cantor, L.B. and Weiss, J.S., Eds., Clinical Optics, Basic and Clinical Science Course, American Academy of Ophthalmology, San Francisco, 167-200.

[16] Al-Akily, S.A. and Bamashmus, M.A. (2008) Causes of Blindness among Adult Yemenis: A Hospital-Based Study. Middle East African Journal of Ophthalmology, 15, 3-6. https://doi.org/10.4103/0974-9233.53367

[17] Waked, N., Fayad, A.M., Fadlallah, A. and El Rami, H. (2012) Keratoconus Screening in a Lebanese Students' Population. Journal Français d' Ophtalmologie, 35, 23-29. https://doi.org/10.1016/j.jfo.2011.03.016

[18] Abu-Amero, K.K., Al-Muammar, A.M. and Kondkar, A.A. (2014) Genetics of Keratoconus: Where Do We Stand? Journal of Ophthalmology, 2014, Article ID: 641708. https://doi.org/10.1155/2014/641708

[19] Rong, S.S., Ma, S.T.U., Yu, X.T., Ma, L., Chu, W.K., Chan, T.C.Y., et al. (2017) Genetic Associations for Keratoconus: A Systematic Review and Meta-Analysis. Scientific Reports, 7, Article No. 4620. https://doi.org/10.1038/s41598-017-04393-2

[20] Rabinowitz, Y.S. (1998) Keratoconus. Survey of Ophthalmology, 42, 297-319. https://doi.org/10.1016/S0039-6257(97)00119-7

[21] Woodward, M.A., Blachley, T.S. and Stein, J.D. (2016) The Association between Sociodemographic Factors, Common Systemic Diseases, and Keratoconus: An Analysis of a Nationwide Heath Care Claims Database. Ophthalmology, 123, 457-465.E2. https://doi.org/10.1016/j.ophtha.2015.10.035

[22] Bawazeer, A.M., Hodge, W.G. and Lorimer, B. (2000) Atopy and Keratoconus: A Multivariate Analysis. British Journal of Ophthalmology, 84, 834-836. https://doi.org/10.1136/bjo.84.8.834

[23] Weed, K.H., MacEwen, C.J., Giles, T., Low, J. and McGhee, C.N. (2008) The Dundee University Scottish Keratoconus Study: Demographics, Corneal Signs, Associated Diseases, and Eye Rubbing. Eye, 22, 534-541.

https://doi.org/10.1038/sj.eye.6702692

[24] McMonnies, C.W. and Boneham, G.C. (2003) Keratoconus, Allergy, Itch, Eye Rubbing and Hand-Dominance. Clinical and Experimental Optometry, 86, 376-384. https://doi.org/10.1111/j.1444-0938.2003.tb03082.x

[25] Romero-Jiménez, M., Santodomingo-Rubido, J. and Wolffsohn, J.S. (2010) Keratoconus: A Review. Contact Lens and Anterior Eye, 33, 157-166. https://doi.org/10.1016/j.clae.2010.04.006

[26] Espandar, L. and Meyer, J. (2010) Keratoconus: Overview and Update on Treatment. Middle East African Journal of Ophthalmology, 17, 15-20.

[27] Cavas-Martínez, F., De la Cruz Sánchez, E., Nieto Martínez, J., Fernández Cañavate, F.J. and Fernández-Pacheco, D.G. (2016) Corneal Topography in Keratoconus: State of the Art. Eye and Vision, 3, Article No. 5. https://doi.org/10.1186/s40662-016-0036-8

[28] de Sanctis, U., Loiacono, C., Richiardi, L., Turco, D., Mutani, B. and Grignolo, F.M. (2008) Sensitivity and Specificity of Posterior Corneal Elevation Measured by Pentacam in Discriminating Keratoconus/Subclinical Keratoconus. Ophthalmology, 115, 1534-1539. https://doi.org/10.1016/j.ophtha.2008.02.020

[29] Li, X., Rabinowitz, Y.S., Rasheed, K. and Yang, H. (2004) Longitudinal Study of the 
Normal Eyes in Unilateral Keratoconus Subjects. Ophthalmology, 111, 440-446. https://doi.org/10.1016/j.ophtha.2003.06.020

[30] Arnalich-Montiel, F., Alió Del Barrio, J.L. and Alió, J.L. (2016) Corneal Surgery in Keratoconus: Which Type, Which Technique, Which Outcomes? Eye and Vision, 3, Article No. 2. https://doi.org/10.1186/s40662-016-0033-y

[31] Katsoulos, C., Karageorgiadis, L., Vasileiou, N., Mousafeiropoulos, T. and Asimellis, G. (2009) Customized Hydrogel Contact Lenses for Keratoconus Incorporating Correction for Vertical Coma Aberration. Ophthalmic and Physiological Optics, 29, 321-329. https://doi.org/10.1111/j.1475-1313.2009.00645.x

[32] Ortiz-Toquero, S. and Martin, R. (2017) Current Optometric Practices and Attitudes in Keratoconus Patient Management. Contact Lens and Anterior Eye, 40, 253-259. https://doi.org/10.1016/j.clae.2017.03.005

[33] Downie, L.E. and Lindsay, R.G. (2015) Contact Lens Management of Keratoconus. Clinical and Experimental Optometry, 98, 299-311. https://doi.org/10.1111/cxo.12300

[34] Kanellopoulos, A.J., Loukas, Y.L. and Asimellis, G. (2016) Cross-Linking Biomechanical Effect in Human Corneas by Same Energy, Different UV-A Fluence: An Enzymatic Digestion Comparative Evaluation. Cornea, 35, 557-561. https://doi.org/10.1097/ICO.0000000000000758

[35] Arora, R. and Lohchab, M. (2019) Pediatric Keratoconus Misdiagnosed as Meridional Amblyopia. Indian Journal of Ophthalmology, 67, 551-552. https://doi.org/10.4103/ijo.IJO 149618

[36] El-Raggal, T.M. (2009) Riboflavin-Ultraviolet A Corneal Cross-Linking for Keratoconus. Middle East African Journal of Ophthalmology, 16, 256-259.

[37] World Health Organization (2018) World Sight Day. World Health Organization, Geneva. www.who.int/blindness/world sight day/en/

\section{List of Abbreviations}

KCN-Keratoconus

SPSS-Statistical Package for the Social Sciences

CT-Corneal topography

RGP-Rigid gas permeable

CXL-Corneal collagen cross-linking 